\title{
Investigation of Antioxidant Activity of Cumin (Cuminum Cyminum L.) by Means of UV-Vis Spectroscopy, Proton Nuclear Magnetic Resonance and Iodometric Method
}

\author{
Mahdi Hajimohammadi*1 ${ }^{\text {, Hoda Ghasemi }}{ }^{1}$ and Atena Vaziri Sereshk ${ }^{2}$ \\ ${ }^{1}$ Faculty of Chemistry, Kharazmi University, G. C, Mofateh, Tehran, Iran. \\ ${ }^{2}$ Department of Chemistry, Faculty of Science, Central Tehran Branch, Islamic Azad University, Shahrak Gharb, Tehran, Iran \\ *Corresponding author: Mahdi Hajimohammadi, Faculty of Chemistry, Kharazmi University, G. C, Mofateh, Tehran, Iran.
}

\begin{abstract}
ARTICLE INFO
Received: April 24, 2020

Published: April 30, 2020

Citation: Mahdi H, Hoda G, Atena Vaziri S. Investigation of Antioxidant Activity of Cumin (Cuminum Cyminum L.) by Means of UV-Vis Spectroscopy, Proton Nuclear Magnetic Resonance and Iodometric Method. Biomed J Sci \& Tech Res 27(3)2020. BJSTR. MS.ID.004491.
\end{abstract}

Keywords: Reactive Oxygen Species; Oleic Acid, UV-Vis Spectroscopy; Cumin, Proton Nuclear Magnetic Resonance

\begin{abstract}
In this study cumin (Cuminum cyminum L.) seed extract was introduced as an efficient natural antioxidant on limitation of reactivity of singlet oxygen $\left({ }^{1} \mathrm{O}_{2}\right)$, hydroxyl radical $(\mathrm{OH} \cdot)$, hydrogen peroxide $\left(\mathrm{H}_{2} \mathrm{O}_{2}\right)$ and superoxide radical $(\mathrm{O} 2 \cdot-)$. Singlet oxygen production and oleic acid oxidation monitored by Proton nuclear magnetic resonance (1H NMR) and iodometric method as a popular method. Also oleic acid oxidation process in the presence of $\mathrm{OH} \cdot$ and $\mathrm{H}_{2} \mathrm{O}_{2}$ were monitored by UV-Vis during the reaction at $\lambda=200-380 \mathrm{~nm}$. UV-Vis spectroscopy as a very convenient method showed in the oleic acid oxidation with $\mathrm{OH} \cdot$ and $\mathrm{H}_{2} \mathrm{O}_{2}$ as Reactive Oxygen Species (ROS), Band gaps of oleic acid as a result of oxidation were compacted in the presence of cumin which demonstrated cumin has high capacity on control of fatty acid against these types of ROS. Also, the rate of oleic acid oxidation by ${ }^{1} \mathrm{O}_{2}$ as a very reactive ROS reduced about $84 \%$ in the presence of $2 \mathrm{ml}$ methanolic extract of cumin (contains $3.01 \mathrm{mg}$ flavonoid). These results reveal that cumin because of its flavonoid compounds can use as a high efficient singlet oxygen scavenger.
\end{abstract}

Abbreviations: BHA: Butylated Hydroxyanisole, TBHQ: Tert-Butyl Hydroquinone, BHT: Butylated Hydroxyl Toluene, PG: Propyl Gallate

\section{Introduction}

ROS is a phrase used to describe ROS and free radicals derived from molecular oxygen such as superoxide $\left(\mathrm{O}_{2}-2\right)$, hydrogen peroxide $\left(\mathrm{H}_{2} \mathrm{O}_{2}\right)$, hydroxyl radical $(\mathrm{OH} \bullet)$ and singlet oxygen $\left({ }^{1} \mathrm{O}_{2}\right)$ [1-3]. High levels of ROS can lead to cellular damage; oxidative stress and DNA damage [4]. Lipids due to the electrophilic inherent can be a target of ROS and converted to lipid hydroperoxides as primary product of fatty acid oxidation [5]. Antioxidants have important role to prevent oxidation biomolecular with inhabitation of Radical Chain Reaction (RCC). Recently, the interest in natural antioxidants has been increased since the application of the most widely used synthetic antioxidants such as Butylated Hydroxyanisole (BHA), Butylated Hydroxyl Toluene (BHT), Tert-Butyl Hydroquinone (TBHQ) and
Propyl Gallate (PG) has been questioned because of possible toxic and carcinogenic components formed during their degradation [6]. Phenolic compounds are the main class of natural antioxidants [7]. Fruits, plants and vegetables and their processing by-products are one of the most essential sources of natural antioxidants due to the abundance of phenolic compounds such as flavonoids [8]. Cumin shown has bronchodilatory, hypotensive, antibacterial, antifungal, analgesic, anti-inflammatory, immuneopotentiating and antioxidant activities [9]. Each ROS as a result of different nature of the electrons has its own characteristics. Dioxygen in its ground state has two unpaired electron in terms of quantum ground state is its triplet [10]. 
Spin rule forbids reaction of singlet oxygen with fatty acids For this purpose, photochemical reactions applied that use porphyrins and metalloporphyrins as regent to require efficient energy to convert air $/{ }^{3} \mathrm{O}_{2}$ to singlet oxygen $/{ }^{1} \mathrm{O}_{2}$, as a very active regent [11-14]. The photosensitized production of singlet oxygen has significance in the areas of the photooxidation of organic compounds, DNA damage, and Photodynamic therapy $[15,16]$ Human skin is largest body organ and it constantly exposed to solar radiation which is capable of inducing the generation of ROS and UV exposure is thought to cause skin aging and skin cancer mainly by singlet oxygen [17]. UVB may produce $02 \bullet-$, and UVA may produce ${ }^{1} \mathrm{O}_{2}$ possibly through chromophores, such as porphyrin in skin [18]. There are few studies on the efficiency of natural antioxidant as 02 $(1 \Delta \mathrm{g})$ quenchers and their roles in the prevention of lipid oxidation in biological systems [19]. Cumin (Cuminum cyminum L.) is a small annual and herbaceous plant belonging to the Apiaceous family. It is one of the popular spices regularly used as a flavoring agent. It is cultivated in Iran, Arabia, India, China, and in the countries bordering the Mediterranean Sea [9]. This project was designed to characterize antioxidant potential of cumin in the oleic acid oxidation process by different ROS especially with singlet oxygen.

\section{Materials and Methods}

\section{Materials}

Oleic acid, ethanol, DMSO, hydrogen peroxide, acetonitrile and $\mathrm{KO}_{2}$ were purchased from Fluka and Merck without further purification. Tetraphenyl porphyrin $\left(\mathrm{H}_{2} \mathrm{TPP}\right)$, ZnTPP and FeTPPC and were synthesized according to the literatures [20]. Methanolic extract of cumin were purchased from Barij Essence Pharmaceutical Company.

\section{Methods}

Sample preparation to oleic acid photooxygenation: $0.2 \mathrm{ml}$ photosensitizers $(0.001 \mathrm{M})$ and $1 \mathrm{ml}$ oleic acid were added to $5 \mathrm{ml}$ acetonitrile in a test tube. Reactions were irradiated with the sun simulator light (288 power LED lamps, 1 W, 2.3 V (59660 LUX)) for 6 hours at room temperature under $1 \mathrm{~atm}$ of bubbling of air in the solution.

Sample preparation to oleic acid oxidation with $\mathrm{H}_{2} \mathrm{O}_{2}$ and $\mathrm{OH} \bullet$ for monitoring with UV-Vis method: $0.1 \mathrm{ml}$ hydrogen peroxide $30 \%$ and $0.1 \mathrm{ml}$ antioxidants (contains $0.23 \mathrm{mg}$ polyphenolic compounds) were added to $5 \mathrm{ml}$ oleic acid $0.001 \mathrm{M}$. The reactions were irradiated by UV light from a high pressure 30W mercury lamp (Philips, $\lambda=$ 200-280nm) for $\mathrm{OH} \bullet$ generation. Sample preparation to oleic acid oxidation with $\mathrm{H}_{2} \mathrm{O}_{2}$ and $\mathrm{OH} \bullet$ by iodometric titration: $0.1 \mathrm{ml}$ hydrogen peroxide $30 \%, 2 \mathrm{ml}$ oleic acid and $2 \mathrm{ml}$ antioxidant (contains $4.6 \mathrm{mg}$ polyphenolic compounds) added to $6 \mathrm{ml}$ ethanol. By irradiation of UV light from a high pressure 30W mercury lamp (Philips, $\lambda=200-280 \mathrm{~nm}$ ) in the reactions $\mathrm{OH} \bullet$ is generated. In order to avoid interference of hydrogen peroxide in the PV (meq $\mathrm{O}_{2} / \mathrm{kg}$ ) measurement, organic media which involves oleic acid oxidation products was extracted and work up by water and chloroform. Superoxide anion radical preparation for oleic acid oxidation: $2 \mathrm{ml}$ oleic acid and $0.44 \mathrm{gr} \mathrm{KO}_{2}$ added to $10 \mathrm{ml}$ DMSO in the presence of $3 \mathrm{ml}$ antioxidant (contains $6.9 \mathrm{mg}$ polyphenolic compounds).

\section{Analytical methods}

$\mathrm{PV}$ (peroxide value, meq $\mathrm{O}_{2} / \mathrm{kg}$ ) of the samples was determined according to the literature [21-27]. Oleic acid oxidation process was monitored by UV-Vis (Shimadzu 2100 spectrophotometer) during the reaction at $\boldsymbol{\lambda}=200-380 \mathrm{~nm}$. $1 \mathrm{H}$ NMR spectra were obtained on a Bruker AMX $300 \mathrm{MHz}$ spectrometer using TMS as internal standard.

\section{Results and Discussion}

In our previous studies, an efficient system for the porphyrinssensitized aerobic oxidation of fatty acids has been developed in the presence of visible light [21-24]. Herein, in continuation of our studies we report oxidative alterations of oleic acid as a result of oxidation with singlet oxygen, superoxide radical, hydrogen peroxide and radical hydroxyl in the presence and absence of cumin as a natural antioxidant. Our target of oxidation oleic acid by different ROS with focus on singlet oxygen (Figure 1), which has few studies on it [18].

Photooxygenation of oleic acid with $\mathrm{H}_{2}$ TPP was investigated as a typical standard sample to evaluate singlet oxygen production and oleic acid oxidation monitored by $1 \mathrm{H}$ NMR and idometric method as a popular method [25]. It is important to note that $1 \mathrm{H}$ NMR and idometric method showed that the oxidation of oleic acid to peroxide product was stopped in the absence of porphyrin (Figure 2 \& Table 1 entry 1 ) or when the irradiation was interrupted (Table 1 entry 2). Accordingly, the presence of a porphyrin, light, and $\mathrm{O}_{2}$ are essential for the conversion of oleic acid to corresponding products (Table 1 entry 3 ). Also, in the presence of N3-, which is a well-known singlet oxygen scavenger [25] oleic acid conversion was inhibited (Table 1, entry 5). Singlet oxygen lifetime is the important issue for conversion of oleic acid to related product during photooxygenation.

According to the literature singlet oxygen lifetime in DMSO is $19 \mu \mathrm{s}, 65 \mu \mathrm{s}$ in acetonitrile and $38 \boldsymbol{\mu} \mathrm{s}$ in ethanol which was correlated with the results in Table 1 entry 3,6 and 7 [26,27]. Also singlet oxygen generation by different photosensitizer and their reactions with the oleic acid obey the order of H2TPP > FeTPPCl > ZnTPP. Paramagnetic metals are claimed to quench singlet oxygen by energy transfer mechanism from oxygen to the low-lying $d$ electron levels and have very short triplet lifetimes (Table 1, entry 8 , 9) [28]. Flavonoid compounds trap singlet oxygen and produce FLA- $\mathrm{O}_{2}$ compound (Figure 3) [29]. According to the (Table 2 entry $3,4,10,11$ ) by increasing amounts of cumin as a source of flavonoid compounds, the oleic acid oxidation rate or PV was considerably decreased. It is important to note, the rate of oleic acid oxidation 
by ${ }^{1} \mathrm{O}_{2}$ as a very reactive ROS reduced about $84 \%$ in the presence of $2 \mathrm{ml}$ methanolic extract of cumin (contains $3.01 \mathrm{mg}$ flavonoid). In continue to investigate antioxidant properties of cumin on $\mathrm{H}_{2} \mathrm{O}_{2}$ and $\mathrm{OH} \bullet$ after oleic acid oxidation reaction with these types of ROS, $\mathrm{H}_{2} \mathrm{O}_{2}$ and $\mathrm{OH} \bullet$ extracted from reaction media. PV results showed cumin can act as an oxidation inhibitor and by the passing time cumin lost its antioxidant ability by facing to $\mathrm{H}_{2} \mathrm{O}_{2}$ and $\mathrm{OH} \bullet$ (Table 2).

Idometric titration as a popular method because of peroxide agent in the cases of $\mathrm{H}_{2} \mathrm{O}_{2}$ and $\mathrm{OH} \bullet$ has been limited. Therefore, in this work UV-Vis method was applied for investigation of antioxidant property of cumin against $\mathrm{H}_{2} \mathrm{O}_{2}$ and $\mathrm{OH} \bullet$. According to the literature oxidation of polyunsaturated fatty acids is accompanied by an increase of absorption in the ultraviolet range (200-380nm) [29]. Lipids containing dienes or polyenes show a shift in their double bond position during oxidation due to isomerization and conjugation formation [30]. It was observed in the presence of cumin as an antioxidant the UV-visible spectra gap spaces of oleic acid after oxidation process with $\mathrm{OH} \bullet$ and $\mathrm{H}_{2} \mathrm{O}_{2}$ was compacted (Figure 4). A and b columns demonstrate gap spaces of oleic acid oxidation at $\lambda=312 \mathrm{~nm}$ by $\mathrm{OH} \bullet$ in the presence and absence of antioxidant. Also, c and d columns demonstrate oleic acid oxidation gap spaces at $\lambda=230 \mathrm{~nm}$ by $\mathrm{H}_{2} \mathrm{O}_{2}$. This results showed in the presence of cumin as an antioxidant absorption gap spaces per $5 \mathrm{~min}$ is less than absorption gap spaces in the absence of cumin for 1 hour oxidation which confirmed cumin has good effect on control of oxidation because of its polyphenol composition and antioxidant activity. Also comparative of UV-vis and iodometric data have been good agreement in the oxidation process. Our investigation of superoxide anion radical was based on PV (Figure 5). Lack of willingness oleic acid's reaction by super oxide caused monitoring products at longer period of time [31]. Results showed cumin had the best effect on limitation oleic acid oxidation during the $16 \mathrm{~h}$ oxidation and its antioxidant effect on $02 \cdot-$ is the more efficient than vitamin $\mathrm{E}$ as one of the best well known lipid soluble antioxidant.

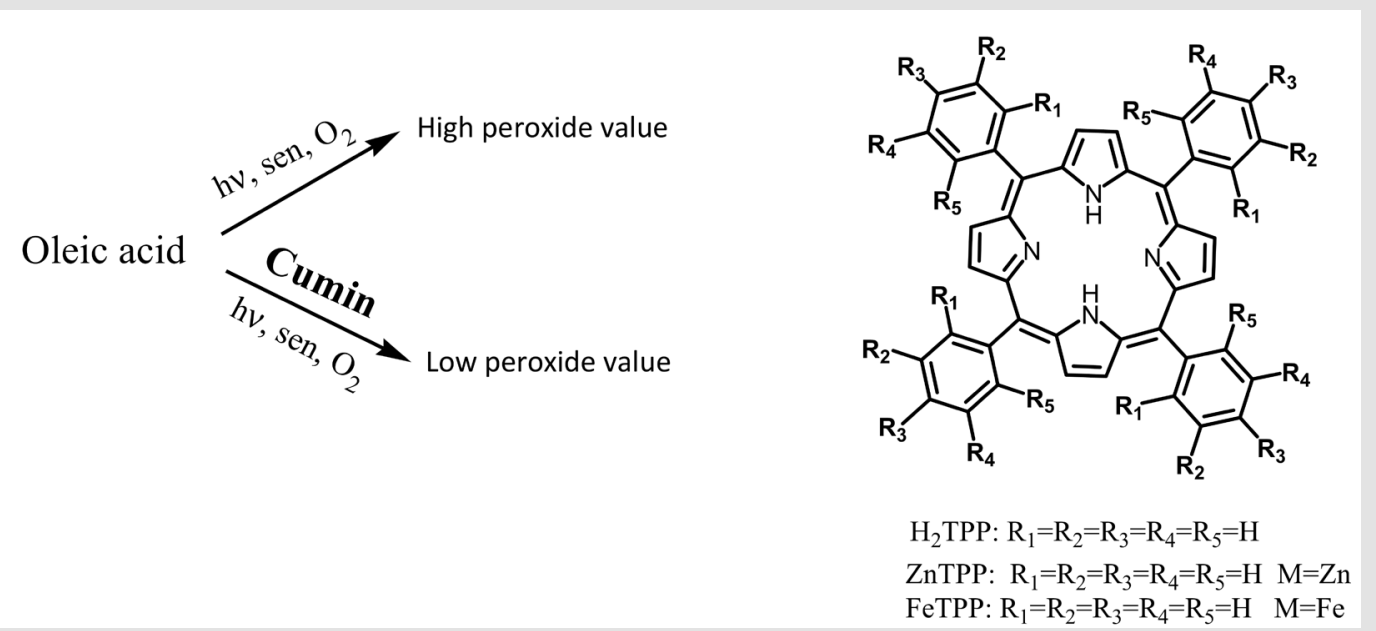

Figure 1: Oleic acid photooxygenation in the presence and absence of cumin antioxidant with photosensitizers (sen) and structure of different applied photosensitizers.

Figure 2: H NMR spectra of oleic acid after photooxygenation in the absence (right) and in the presence (left) of H2TPP as a photosensitizer. 


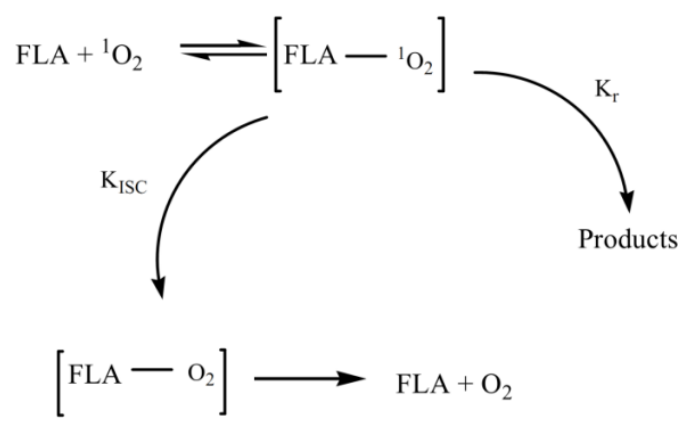

Figure 3: The mechanism of flavonoids barricade against singlet oxygen.

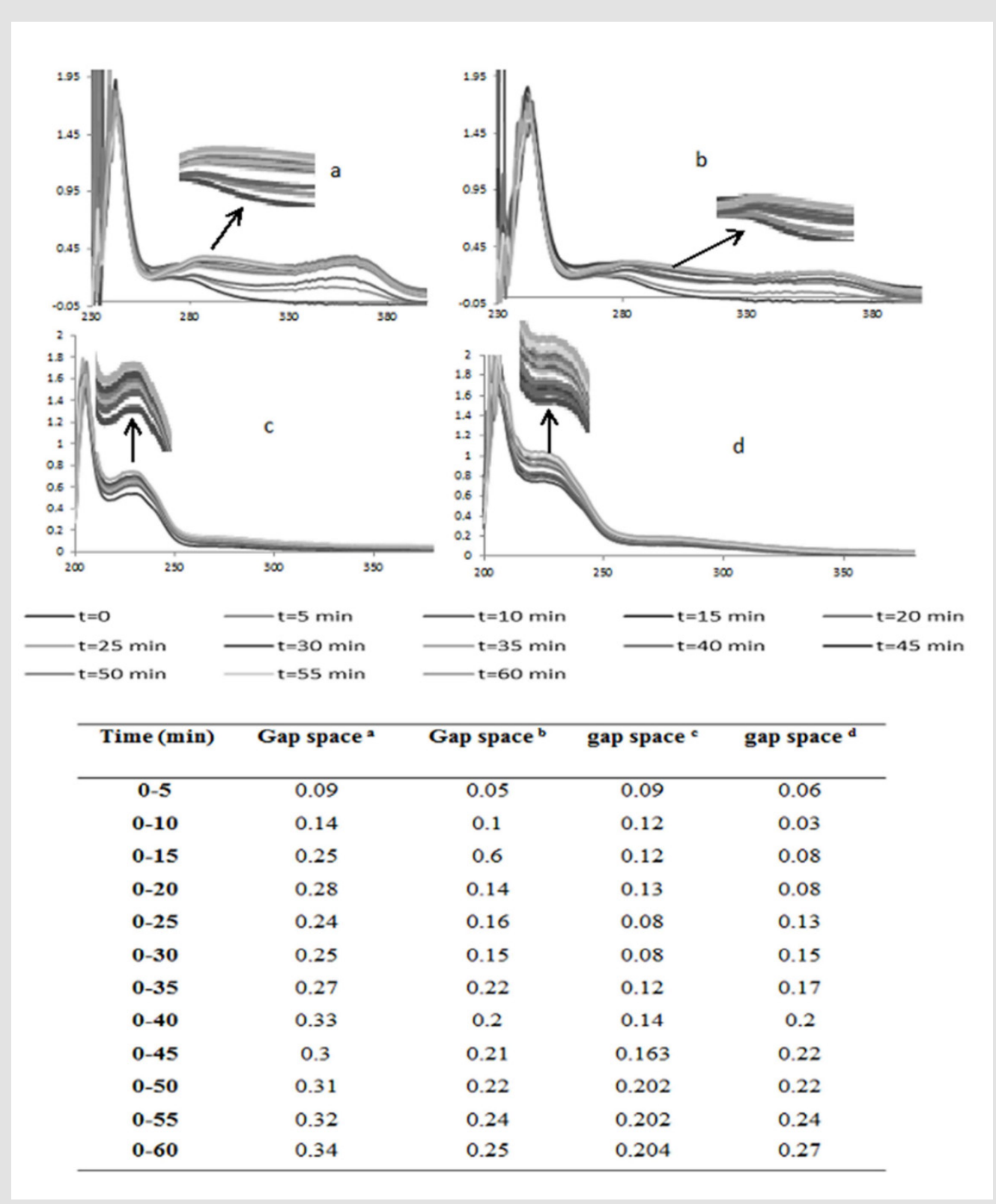

Figure 4: UV-visible spectra and absorption gap spaces of (a) Oleic acid oxidation process by OH• (b) Oleic acid oxidation process by $\mathrm{OH} \bullet$ in the presence of cumin. (c) Oleic acid oxidation process by $\mathrm{H}_{2} \mathrm{O}_{2}$ (d) oleic acid oxidation process by $\mathrm{H}_{2} \mathrm{O}_{2}$ in the presence of cumin. 


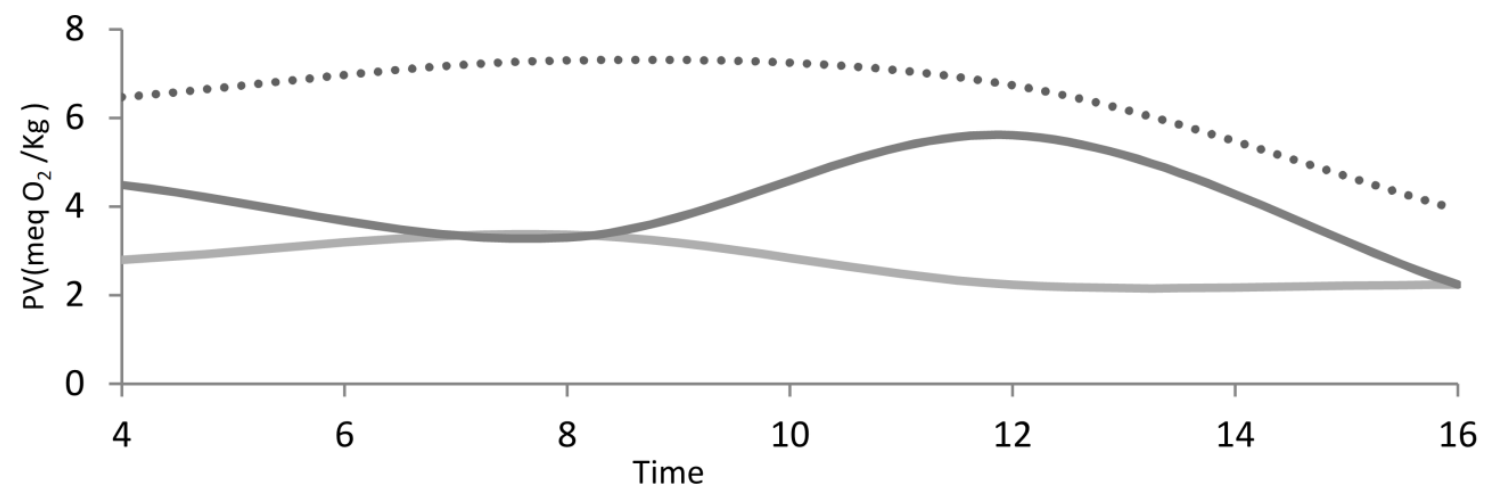

Figure 5: Oleic acid oxidation by superoxide anion radical in the absence of antioxidant (dotty line), oleic acid oxidation in the presence of cumin (contains $6.9 \mathrm{mg}$ polyphenolic compounds) (light gray line) and oleic acid oxidation in the presence of vitamin E (contains $20 \mathrm{mg}$ of natural alpha-tocopherol) (dark gray line).

Table 1: PV number of oleic acid oxidation by singlet oxygen in different conditions.

\begin{tabular}{|c|c|c|}
\hline Entry & Condition & PV (meq $\left.\mathbf{~}_{2} / \mathbf{k g}\right)$ \\
\hline $\mathbf{1}$ & oleic acid $+\mathrm{CH}_{3} \mathrm{CN}+$ air + light & Trace \\
\hline $\mathbf{2}$ & oleic acid $+\mathrm{CH}_{3} \mathrm{CN}+\mathrm{H}_{2} \mathrm{TPP}+$ air & Trace \\
\hline $\mathbf{3}$ & oleic acid $+\mathrm{CH}_{3} \mathrm{CN}+\mathrm{H}_{2} \mathrm{TPP}+$ light + air & 356.17 \\
\hline $\mathbf{4}$ & oleic acid $+\mathrm{CH}_{3} \mathrm{CN}+\mathrm{H}_{2} \mathrm{TPP}+$ light + air + cumin & 361.79 \\
\hline $\mathbf{5}^{\mathbf{b}}$ & oleic acid $+\mathrm{CH}_{3} \mathrm{CN}+\mathrm{H}_{2} \mathrm{TPP}+\mathrm{NaN}+$ light + air & 49.43 \\
\hline $\mathbf{6}$ & oleic acid $+\mathrm{DMSO}+\mathrm{H}_{2} \mathrm{TPP}+$ light + air & 64.44 \\
\hline $\mathbf{7}$ & oleic acid $+\mathrm{C}_{2} \mathrm{H}_{5} \mathrm{OH}+\mathrm{H}_{2} \mathrm{TPP}+$ light + air & 258.42 \\
\hline $\mathbf{8}$ & oleic acid $+\mathrm{CH}_{3} \mathrm{CN}+\mathrm{ZnTPP}+$ light + air & 37.07 \\
\hline $\mathbf{9}$ & oleic acid $+\mathrm{CH}_{3} \mathrm{CN}+\mathrm{FeTPPCl}+$ light + air & 35.95 \\
\hline $\mathbf{1 0}$ & oleic acid $+\mathrm{CH}_{3} \mathrm{CN}+\mathrm{H}_{2} \mathrm{TPP}+$ light + air + cumin & 292.13 \\
\hline $\mathbf{1 1}^{\mathbf{c}}$ & oleic acid $+\mathrm{CH}_{3} \mathrm{CN}+\mathrm{H}_{2} \mathrm{TPP}+$ light+air + cumin & 73.03 \\
\hline
\end{tabular}

Note: (a) $0.0031 \mathrm{~mol}$ oleic acid, $0.5 \mathrm{ml}$ antioxidant (contains $0.75 \mathrm{mg}$ flavonoid), $5 \mathrm{ml}$ solvent, $0.2 \mathrm{ml}(0.001 \mathrm{M})$ sensitizer, air (1atm) and 288 power LED lamps, $1 \mathrm{~W}, 2.3 \mathrm{~V}$ (59660 LUX). (b) $0.01 \mathrm{gr}$ sodium azide applied as singlet oxygen scavenger. (c) $1 \mathrm{ml}$ antioxidant (contains $1.5 \mathrm{mg}$ flavonoid). (d) $2 \mathrm{ml}$ antioxidant (contains $3.01 \mathrm{mg}$ flavonoid).

Table 2: The peroxide number (meq $\mathrm{O} 2 / \mathrm{kg}$ ) of oleic acid oxidation by $\mathrm{H}_{2} \mathrm{O}_{2}$ and $\mathrm{OH}$.

\begin{tabular}{|c|c|c|c|}
\hline Entry & Conditions & Time= $\mathbf{h}$ & Time= $\mathbf{h}$ \\
\hline $\mathbf{1}$ & oleic acid $+\mathrm{H}_{2} \mathrm{O}_{2}+$ Ethanol & 50.56 & 28.09 \\
\hline $\mathbf{2}$ & oleic acid $+\mathrm{H}_{2} \mathrm{O}_{2}+$ antioxidant + Ethanol & 33.71 \\
\hline $\mathbf{3}^{\mathbf{b}}$ & oleic acid+ $\mathrm{OH}^{+}+$Ethanol & 21.86 & 0 \\
\hline $\mathbf{4}^{\mathbf{c}}$ & oleic acid $+\mathrm{OH}^{+}+$antioxidant+ Ethanol & 16.86 & 0 \\
\hline
\end{tabular}

Note: (a) $0.0063 \mathrm{~mol}$ oleic acid, $8 \mathrm{ml}$ ethanol, $0.1 \mathrm{ml} \mathrm{H} \mathrm{O}_{2}(30 \%), 2 \mathrm{ml}$ cumin antioxidant (contain $4.6 \mathrm{mg}$ polyphenolic compounds). $(b, c)$ The reactions were irradiated by UV light from a high pressure $30 \mathrm{~W}$ mercury lamp (Philips, $\lambda=200-280 \mathrm{~nm}$ ). 


\section{Conclusion}

Because of ROS actions, human has been suffering from many new and unknown diseases such as cancer, Alzheimer's disease, skin disorders, etc. Side effects of commercial antioxidants turn broaden our view on using new herbal and natural source of flavonoid and polyphenol compounds. In this study cumin as a natural antioxidant showed that it has efficient role on restricting or limitation of fatty acid oxidation by different ROS. In general, with different experimental methods such as UV-vis spectroscopy, iodometric titration and 1H NMR spectroscopy, cumin showed has high antioxidant capacity agains ${ }^{1} \mathrm{O}_{2}$ and the other ROS.

\section{Conflicts of Interest}

The authors declare that they have no conflict of interest.

\section{Acknowledgement}

We gratefully acknowledge financial support from the Research Council of Kharazmi Universiy.

\section{References}

1. Zhou Z, Song J, Tian R, Yang Z, YuG, Lin L, et al. (2017) Activatable Singlet Oxygen Generation from Lipid Hydroperoxide Nanoparticles for Cancer Therapy. Angew Chem Int Ed Engl 56: 6492-6496.

2. Wang SY, Jiao H Agric (200) Scavenging capacity of berry crops on superoxide radicals, hydrogen peroxide, hydroxyl radicals, and singlet oxygen. Food Chem 48(11): 5677-5684.

3. Egler J, Lang F (2017) Triggering of Eryptosis, the Suicidal Erythrocyte Death, by Perifosine. Cell Physiol Biochem 41(6): 2534-2544.

4. Mates JM (2000) Effects of antioxidant enzymes in the molecular control of reactive oxygen species. Toxicology 153(1-3): 83-104.

5. Korytowski W, SchmittJC, Girotti AW (2010) Surprising Inability of Singlet Oxygen-generated 6-Hydroperoxycholesterol to Induce Damaging Free Radical Lipid Peroxidation in Cell Membranes. Photochem Photobiol 86(4): 747-751.

6. Lee JH, Jung MY (2010) Direct spectroscopic observation of singlet oxygen quenching and kinetic studies of physical and chemical singlet oxygen quenching rate constants of synthetic antioxidants (BHA, BHT, and TBHQ) in methanol. J Food Sci 75: 506-513.

7. Rebey IB, Zakhama N, Karoui IJ, Marzouk B (2012) Polyphenol Composition and Antioxidant Activity of Cumin (Cuminum Cyminum L) Seed Extract under Drought. J Food Sci 77(6): 34-39.

8. O'Hara M, Kiefer D, Farrell K, Kemper K (1998) A review of 12 commonly used medicinal herbs. Arch. Fam. Med 7: 523-36.

9. Thippeswamy NB, Naidu KA (2005) Antioxidant potency of cumin varieties cumin, black cumin and bitter cumin on antioxidant systems. Eur Food Res Technol 220(5): 472-476.

10. Min DB, Boff JM (2002) Chemistry and reaction of singlet oxygen in foods. Compr Rev Food Sci Food Saf 1: 58-72.

11. Nam W (2007) High-valent iron (IV)-oxo complexes of heme and nonheme ligands in oxygenation reactions. Acc. Chem. Res 40(7): 522

12. Hendrickson DN, Kinnaird MG, Suslick KS (1987) Photochemistry of $(5,10,15,20$-tetraphenylporphyrinato) iron (III) halide complexes, Fe (TPP)(X). J Am Chem Soc 109: 1243-1244.
13. Peterson MW, Richman RM (1985) Photodisproportionation of (mu.oxo) bis ((tetrakis (4-carboxyphenyl) porphinato) iron (III). Inorg. Chem 24(5): 722-725.

14. DeRosa M, Crutchley R (2002) Photosensitized singlet oxygen and its applications. Coord. Chem. Reviews 233: 351-371.

15. Greer A (2006) Christopher Foote's discovery of the role of singlet oxygen [102 $(1 \Delta \mathrm{g})]$ in photosensitized oxidation reactions. Acc. Chem. Res 39(11): 797-804.

16. Hajimohammadi M, Safari N, Mofakham H, Deyhimi F (2011) Highly selective, economical and efficient oxidation of alcohols to aldehydes and ketones by air and sunlight or visible light in the presence of porphyrins sensitizers. Green Chem 13: 991-997.

17. Berneburg M, Plettenberg H, Medve-Konig K, Pfahlberg A, Gers-Barlag $\mathrm{H}$, et al. (2004) Induction of the photoaging-associated mitochondrial common deletion in vivo in normal human skin. J. Invest. Dermatol 122(5): 1277-1283.

18. Terao J, Minami Y, Bando N (2011) Singlet molecular oxygen-quenching activity of carotenoids: relevance to protection of the skin from photoaging. J Clin Biochem Nutr 48(1): 57-62.

19. Niki E (2015) Lipid oxidation in the skin. Free Radic Res 49: 827-834.

20. Lindsey JS, Wagner RW (1989) Investigation of the synthesis of orthosubstituted tetraphenylporphyrins. J Org Chem 54(1): 828-836.

21. Hajimohammadi M, Vaziri Sereshk A, Schwarzinger C, Knör G (2018) Suppressing effect of 2-nitrobenzaldehyde on singlet oxygen generation, Fatty Acid Photooxidation, and Dye-Sensitizer Degradation. Antioxidants 7: 194.

22. Hajimohammadi M, Nosrati P (2018) Scavenging effect of pasipay (passiflora incarnate L.) on singlet oxygen generation and fatty acid photooxygenation. Food Science \& Nutrition 6: 1670-1675.

23. Hajimohammadi M, Khalaji Verjani M (2018) Dill Is an Efficient Antioxidant Against ROS Specially Singlet Oxygen in the Oleic Acid Media. BJSTR 21(5): 16122-16127.

24. Hajimohammadi M, Ahmadi Khamesi Z, Nosrati P, Zanjirani S, Pureisa Mona (2019) Evaluation of Singlet Oxygen Scavenging Capacity of Peppermint (Mentha Piperita L.), Marjoram (Origanum Majorana L.), Rosemary (Rosmarinus Officinalis L.) And Sage (Salvia Officinalis L.) on Fatty Acid Photooxidation. Journal of Food Nutrition And Metabolism 2: $2-5$.

25. Barthel G, Grosch W (1974) Peroxide value determination comparison of some methods. J Am Oil Chem Soc 51: 540-544.

26. Chen Y, Xu S, Li L (2001) Active oxygen generation and photo-oxygenation involving temporfin (m-THPC). Dyes Pigm 51: 63-69.

27. Bressan M, Morvillo A (1989) Alkene epoxidation by ruthenium (II) phosphine complexes. A kinetic investigation. Inorg Chem 28: 950-953.

28. Bonnett R, Martinez G (2001) Tetrahedron Lett 57: 9513.37.

29. Majer P, Neugart S, Krumbein A, Schreiner M, Hideg É (2014) Singlet oxygen scavenging by leaf flavonoids contributes to sun-light acclimation in Tilia platyphyllos. Environmental and Experimental Botany 100: 1-9.

30. Vieira TMFS, Regitano-dArce MAB (1999) Ultraviolet spectrophotometric evaluation of corn oil oxidative stability during microwave heating and oven test. J Agric Food Chem 47: 2203-2206.

31. Augusto O, Miyamoto S (2011) Oxygen Radicals and Related Species. In Principles of Free Radical Biomedicine. Nova Science Publishers 1: 1-23. 
ISSN: 2574-1241

DOI: 10.26717/BJSTR.2020.27.004491

Mahdi Hajimohammadi. Biomed J Sci \& Tech Res

CC (i) This work is licensed under Creative Submission Link: https://biomedres.us/submit-manuscript.php

$\begin{array}{ll}\text { BIOMEDICAL } & \text { Assets of Publishing with us } \\ \text { RESEARCHES } & \text { - Global archiving of articles } \\ \text { - Immediate, unrestricted online access } & \text { - Rigorous Peer Review Process } \\ & \text { - Authors Retain Copyrights } \\ & \end{array}$

